\title{
OS CENTROS DE INTELIGÊNCIA DA JUSTIÇA FEDERAL E SEU PAPEL NA PREVENÇÃO E NO TRATAMENTO DE LITÍGIOS
}

\author{
Carlos Marden Cabral Coutinho ${ }^{1}$ \\ Cíntia Brunetta ${ }^{2}$
}

\section{RESUMO}

O presente trabalho pretende analisar a criação dos Centros de Inteligência da Justiça Federal como forma de buscar uma solução democrática para a crise que afeta o Poder Judiciário brasileiro. Na sequência, expor-se-á a lógica do Sistema Multiportas, com destaque para a figura dos referidos Centros, instituídos para proporcionar maior racionalidade e operacionalidade ao funcionamento do Judiciário. Após, far-se-á uma análise da configuração das novas estruturas judiciais, argumentando que elas se mostram importantes instrumentos para a prevenção de litígios, notadamente por seu caráter dialógico e democrático. Por fim, tecer-se-ão alguns comentários a respeito do futuro de tais iniciativas.

Palavras-chave: Poder Judiciário. Centros De Inteligência. Sistema Multiportas. Justiça Federal. Prevenção De Litígios.

\section{THE FEDERAL JUDICIAL CENTER OF INTELLIGENCE AND ITS ROLE IN THE PREVENTION AND TREATMENT OF JUDICIAL DISPUTES}

\begin{abstract}
This article aims to study the Federal Judicial Center of Intelligence as a way to pursue a democratic solution for the crisis that affects the brazilian Judiciary. It is intended to reveal the logic behind the Multiport System, with emphasis to the role played by the aforementioned Center, created to provide more rationality to the brazilian Justice. An analysis will be carried out about the configuration of the new structure, arguing that it is an important tool in favor of disputes prevention, specially for its dialogic dimension. At the end, comments will be expressed about the future of this initiative.
\end{abstract}

Keywords: Judiciary System. Federal Judicial Center Of Intelligence. Multiport System. Federal Justice. Disputes Prevention.

\section{Introdução.}

O Poder Judiciário brasileiro enfrenta, atualmente, uma das maiores crises da sua história. Segundo o relatório "Justiça em Números", do Conselho Nacional de Justiça, embora o número de casos resolvidos (sentenças prolatadas ou processos baixados) aumente a cada

\footnotetext{
${ }^{1}$ Possui graduação em Direito pela Universidade Federal do Ceará (2000), Especialização em Direito (Processo Civil) pela Universidade Federal do Ceará, Mestrado em Direito (Ordem Jurídica Constitucional) pela Universidade Federal do Ceará (2007) e Doutorado (Direito Processual) pela Pontíficia Universidade Católica de Minas Gerais - PUC Minas (2014).

${ }^{2}$ Graduada em Direito pela Universidade Federal do Ceará (UFC). MBA em Poder Judiciário pela Fundação Getúlio Vargas. Mestranda em Direito pela Unichristus. Juíza Federal. Email:cbrunetta@hotmail.com

Revista de Política Judiciária, Gestão e Administração da Justiça | e-ISSN: 2525-9822 | Salvador | v. 4 | n. 1 | p. 41 - 57 | Jan/Jun. 2018
} 
ano, também aumenta o número de feitos pendentes de julgamento (que, no ano de 2016 alcançou a marca de 79 milhões) e, consequentemente, da taxa de congestionamento respectiva.

Assim, quando se fala no sistema judicial contemporâneo, questões como seu papel dentro da sociedade e a própria noção da expressão acesso à justiça são colocados na mesa de discussão.

De fato, se não pensada a Justiça em termos de seu "decesso" (ALVIM, 1989), não apenas de seu acesso, mas de término do conflito levado em juízo, de nada servem sistemas de protocolamento drive-thru, em que o advogado sequer sai do carro para dar entrada em uma petição inicial (existente, por exemplo, no Superior Tribunal de Justiça e na Seção Judiciária do Ceará), ou sistemas de processo eletrônico (que remontam ao ano de 2003), em que o próprio carro é dispensável, podendo o ajuizamento das novas ações ser feito, mesmo de madrugada, no conforto da casa ou do escritório do subscritor.

Foi com essa percepção que, em 19 setembro de 2017, o Conselho Nacional de Justiça editou a Portaria 2017/00369 criando o Centro Nacional de Inteligência da Justiça Federal, com as finalidades, dentre outras, de trabalhar na prevenção de demandas judiciais repetitivas ou de massa, fomentar a implementação de medidas preventivas e de projetos de soluções alternativas de conflitos e propor soluções judiciais e administrativas para o manejo de litígios.

Tal portaria veio ao encontro do item 4 do macrodesafio do Planejamento Estratégico do Conselho Nacional de Justiça para os anos 2015/2020 "gestão de demandas repetitivas e grandes litigantes", o qual se refere à redução do acúmulo de processos relativos a litigância serial, advinda dos entes públicos e sistema financeiro, entre outros, e partiu da percepção de que o fenômeno processual denominado "demandas repetitivas" contra o Poder Público representa sensível problema da Justiça brasileira consubstanciado no ajuizamento de demandas semelhantes (mesma tese jurídica) por centenas ou milhares de vezes, tendo, como objeto principal, ações e omissões da Administração Pública.

O presente artigo se propõe a apontar algumas questões relevantes em relação à criação dos Centros de Inteligência, como, por exemplo, o que motivou sua instituição, o que a mesma representa em termos de reformulação da função judicial clássica e quais seus objetos de estudo. A escolha desse tema para a pesquisa foi motivada pelo interesse nos novos papéis assumidos pelo Judiciário no tratamento de litígios, ante o reconhecimento, pelo próprio Poder, da situação de litigiosidade exacerbada vivenciada nos dias de hoje. 
No primeiro e segundo tópicos, analisar-se-á a conjuntura em que foram criados os Centros de Inteligência e a proposta de diálogo democrático com a sociedade a eles associada, culminando com a percepção de que a Justiça brasileira assumiu seu papel inserida dentro do sistema e não isolada.

Falar-se-á, assim, da crise do Poder Judiciário e da ideia surgida neste contexto de implantação do chamado sistema multiportas como política pública de acesso à justiça, reconhecendo que o sistema judicial tem mais do que a responsabilidade de impor, por meio da força e de medidas coercitivas, uma só decisão considerada justa e correta

Por fim, no terceiro tópico, a proposta é abordar algumas propostas concretas associadas às inéditas estruturas judiciais e alguns desafios desta nova forma de atuação judicial, como preservação do desenho institucional próprio e do princípio da separação de poderes.

A metodologia empregada no desenvolvimento do texto é descritivo-documental. Como se trata de inovação no sistema de justiça brasileiro, inexistem bibliografia específica acerca do tema, a maior fonte de pesquisa é a própria regulamentação dos Centros de Inteligência e sua produção.

Ao final do trabalho, pretende-se ter dado uma pequena contribuição na compreensão da inovadora estrutura judicial que são os Centros de Inteligência e a tentativa de sistematização da matéria servirá como um guia para futuros estudos.

\section{A crise do Poder Judiciário e o Sistema Multiportas.}

Desde 2004, o Conselho Nacional de Justiça se propõe a fazer uma radiografia do Poder Judiciário e divulga, anualmente, estatísticas e indicadores para diagnóstico e mapeamento dos diversos ramos da Justiça brasileira.

Em setembro de 2017, foi lançada a $13^{\mathrm{a}}$ edição do projeto chamado "Justiça em números", considerando o ano-base de 2016, e os dados trazidos são estarrecedores. 109,1 milhões de processos tramitaram pela Justiça durante 2016 e 79,7 milhões continuam em andamento. Mais do que isso, a despesa total com o Poder Judiciário foi na ordem de $\mathrm{R} \$ 84.846 .934 .555$, sendo $89,5 \%$ deste valor destinado ao custeio de recursos humanos ( $\mathrm{R} \$$ 75.948.590.205). Tais números são assustadores. Porém, não são surpreendentes.

Desde o início da coleta de dados, é possível se observar o que Mancuso (MANCUSO, 2015) chama de "crise numérica dos processos judiciais". Em seu livro 
"Acesso à Justiça: condicionantes legítimas e ilegítimas", o referido doutrinador aponta as supostas concausas para a crise numérica que noticia e elenca, entre várias outras, a cultura demandista, os grandes litigantes e, especialmente, o que chama de gigantismo judiciário.

Em resumo, defende que o Judiciário se expande para atender o suposto clamor público pelo acesso à justiça e, assim, retroalimenta a demanda e incentiva a cultura judiciarista:

[O Judiciário] Fomenta a contenciosidade ao interno da coletividade [...], cria focos de tensão com o Executivo, na medida em que este é cada vez mais instado a disponibilizar novos e maiores recursos orçamentários, labora contra o vero sentido de cidadania, que, ao menos num primeiro momento, sinaliza que as pessoas físicas e jurídicas tentem ajustar suas pendências diretamente [...] e dificulta as atividades de controle e planejamento dos órgãos jurisdicionais (MANCUSO, 2015).

Ainda mais, alerta Mancuso que a tentativa de resolver o problema da crescente judicialização e da taxa de congestionamento a qualquer preço conduz à oferta da justiça em padrão massivo, estratégia que, aparentemente, serve de resposta imediata aos clamores da sociedade pela resposta estatal, mas não se revela adequada a médio e longos prazos (MANCUSO, 2015).

Foram estas percepções e angústia, resumidas tão bem pelo citado processualista, que acabaram permeando um debate nacional sobre a responsabilidade do Poder Judiciário pela cultura demandista instaurada no país. Este debate teve por objeto, especialmente, uma reflexão acerca do papel do juiz - e do Poder Judiciário - frente aos conflitos sociais, econômicos e políticos cada vez mais complexos e passou-se a reconhecer que, indubitavelmente, os horizontes da jurisdição precisavam ser ampliados para além da análise do conflito individual resolvido através de uma decisão tradicional de command and control, em prol de uma justiça mais democrática voltada à real pacificação social.

O conflito, na verdade, é universal e, ainda que distinto em cada cultura, é o resultado do embate permanente dos indivíduos pelos mesmos objetivos, direitos e recursos. Apesar de distinta em virtude das diferenças culturais patentes, a resolução dos conflitos tem uma nota comum, construída a partir da análise das contradições e contribuições dadas pelas diversas maneiras que diferentes culturas tendem a gerenciar as tensões sociais, políticas e culturais: a sua triangularidade. 
A triangulação, a utilização de um terceiro indivíduo, ou grupo, é tão antiga quanto a comunicação humana. o eterno triângulo, como aponta Augsberger (AUGSBERGER, 1992), está presente tanto na origem como na solução do conflito e o número de triângulos tende a crescer quanto mais se expande o conflito (todos buscam, eternamente, aliados para suas questões).

No momento de tensão, um terceiro sempre é levado a aliviar o conflito proporcionando apoio para algum dos lados (uma opção não muito funcional) ou para ambos (uma escolha mais promissora). Quando o terceiro se recusa a formar uma coalizão com um dos vértices do triângulo, um novo desenho se forma3, no qual este indivíduo imparcial pode auxiliar os envolvidos a se movimentar em direção a uma solução mutuamente satisfatória do conflito.

O que essa triangularidade quer dizer? Bem, pode-se encarar por dois enfoques distintos. O primeiro enfoque e mais óbvio seria a desejável participação de um terceiro na solução do litígio, alguém de fora, imparcial, que auxilie os conflitantes a tentar enxergar a posição do outro, identificando seus conflitos e interesses, e a construir, em conjunto, alternativas de solução.

O segundo enfoque seria a necessária participação ativa de todos os envolvidos na solução do conflito a ser pacificado. Ou seja, eliminar a passividade da espera de uma decisão a ser tomada por um indivíduo de fora da lide e participar da construção de uma solução conjunta da controvérsia (no triângulo, existe ponto de contato entre todos os vértices, todos eles se interligam e se comunicam).

Neste passo, entende-se que é natural, para todas as sociedades, querer que aqueles envolvidos em um conflito resolvam suas próprias questões sozinhos. Porém, apesar de natural, é praticamente impossível, na maioria dos casos, eliminar a hostilidade e a perda da confiança para caminhar em direção à solução conjunta. Afinal, quem disputa algo está na pior posição para resolver a disputa.

\footnotetext{
${ }^{3}$ Sobre o assunto, é bom registrar que alguns doutrinadores, a exemplo de AUGSBERGER, defendem que se o terceiro indivíduo optar pela abordagem construtiva na intervenção do conflito, o triângulo daria lugar a uma trindade (horizontal), mas fez-se no presente trabalho a opção pela permanência da figura do triângulo, não só por ser mais familiar ao operador do direito (a "triangularidade da relação processual"), mas, também, por entender que, especialmente que, no âmbito judicial, o terceiro interveniente tem, necessariamente, um papel mais destacado na autocomposição.

Revista de Política Judiciária, Gestão e Administração da Justiça | e-ISSN: 2525-9822 | Salvador | v. 4 | n. 
No entanto, apesar de reconhecer a facilitação da solução da lide através da intervenção de um terceiro (triangularidade), é importante ter em mente que a construção da melhor solução não pode ser algo imposto aos envolvidos, a menos que isso seja absolutamente necessário (no caso de impossibilidade jurídica, técnica ou emocional de conciliação).

Essa proposta de maior democratização da Justiça e mesmo de reformulação da função judicial clássica começou a ser concretizada no Brasil, dentro do Poder Judiciário, a partir da Resolução n. 125/2010 do Conselho Nacional de Justiça, que dispôs sobre a Política Judiciária Nacional de tratamento adequado dos conflitos de interesses no âmbito do Poder Judiciário.

O referido texto normativo consolidou a ideia de que:

Cabe ao Judiciário estabelecer política pública de tratamento adequado dos problemas jurídicos e dos conflitos de interesses, que ocorrem em larga e crescente escala na sociedade, de forma a organizar, em âmbito nacional, não somente os serviços prestados nos processos judiciais, como também os que possam sê-lo mediante outros mecanismos de solução de conflitos, em especial dos consensuais, como a mediação e a conciliação.

Ou seja, a partir deste momento, ficou claro que, para a Justiça brasileira, não é função jurisdicional apenas prolatar a decisão que diz o direito. Muito pelo contrário, cabe ao Poder Judiciário dar tratamento adequado aos problemas e conflitos postos à sua apreciação.

E, assim, é adotado o chamado sistema multiportas de solução de conflitos, oferecendo ao jurisdicionado diversas ferramentas, processuais ou não, de resolução do litígio, partindo do pressuposto, constante nos considerandos da referida resolução de que "o direito de acesso à Justiça, previsto no art. 50, XXXV, da Constituição Federal além da vertente formal perante os órgãos judiciários, implica acesso à ordem jurídica justa e a soluções efetivas".

Mais ainda, o sistema multiportas vem ao encontro da chamada terza ondata do acesso à justiça chamada por Cappelletti (CAPELLETTI, 1988) de novo enfoque de acesso à justiça (do acesso à representação em juízo a uma concepção mais ampla de acesso à justiça), que sintetiza as duas primeiras (representação legal dos pobres e hipossuficientes e representação dos direitos difusos), concatenando-as de modo a construir um todo coeso. Na lição do mestre italiano: 
Esse enfoque encoraja a exploração de uma ampla variedade de reformas, incluindo alterações nas formas de procedimento,mudanças na estrutura dos tribunais, o uso de pessoas leigas ou paraprofissionais, tanto como juízes quanto como defensores, modificações no direito substantivo destinadas a evitar litígios ou facilitar sua solução e a utilização de mecanismos privados ou informais de solução dos litígios. Esse enfoque, em suma, não receia inovações radicais e compreensivas, que vão muito além da esfera de representação judicial.

Trata-se de transformar a estrutura judicial, desburocratizar tribunais e procedimentos, buscar novos ou alternativos métodos para decidir as causas, com a instituição de incentivos econômicos para a solução de litígios fora dos fóruns e cortes e simplificar o próprio Direito.

Implica numa ampla cadeia de reformas que, necessariamente, passam pela alteração da legislação, modernização dos instrumentos operacionais e, acima de tudo, mudança da mentalidade do operador do Direito.

Como conseqüência de tal onda, mudanças começaram a ser necessárias nos escopos da ação, do processo e da jurisdição, que passaram a constituir-se em conduto importante de participação política através do Judiciário e em instrumentos de racionalização do poder político econômico e social e de mediação dos conflitos de interesses e tensões sociais.

Neste linha, ficou estabelecido, a partir da citada Resolução n. 125/2010 do Conselho Nacional de Justiça, que aos órgãos judiciários incumbe oferecer outros mecanismos de soluções de controvérsias, em especial os chamados meios consensuais, como a mediação e a conciliação, bem assim prestar atendimento e orientação ao cidadão. Ou seja, não mais adianta que o Judiciário decida e imponha a decisão que considera justa, precisa ele dar ao cidadão a opção de soluções alternativas para o conflito, "com vista à boa qualidade dos serviços e à disseminação da cultura de pacificação social" (artigo $2^{\circ}$, parte final).

E é dentro desse novo conceito de jurisdição e de resolução de conflitos de interesses e problemas jurídicos que surgem os Centros de Inteligência da Justiça Federal, com objetivos voltados à compreensão ampla do perfil de litigiosidade, à busca de rápida solução para litígios que estejam impactando negativamente uma ou mais unidade jurisdicional e à elaboração de propostas e ações coordenadas com instituições públicas visando ao combate da fragmentação na resolução dos conflitos. 


\section{A tentativa de democratização e dialogicidade na criação dos Centros de Inteligência}

Alguns riscos são apontados quando se propõe uma revisita, uma reformulação, da função a ser exercida por algum dos poderes constituídos, notadamente pelo Judiciário. Isso porque, associada à própria noção de separação de poderes, encontra-se a discussão sobre capacidade institucional, limitação de tempo e recursos, ausência de vocação democrática (Judiciário como força contramajoritária) e, claro, potencial violação à separação de Poderes.

Segundo Diego Arguelhes e Fernando Leal (ARGUELHES \& Leal, 2011):

$\mathrm{O}$ argumento das capacidades institucionais pressupõe uma determinada concepção de separação de poderes e de desenho institucional, segundo a qual diferentes funções devem ser alocadas, tanto quanto possível, para o nível de governo ou da sociedade que possa exercê-los melhor. Sob tal perspectiva, a palavra chave na distribuição de poderes é especialização.

Assim, a princípio, alega-se que faltaria ao Judiciário expertise para lidar com questões com repercussões de uma atuação não pontual a nível econômico e social, e, ainda mais, tempo e recursos para assumir mais do que sua função clássica. A atuação atípica, desta forma, poderia acarretar impactos irremediáveis na conjuntura social, política e econômica do Estado e a conduta deslocada (além de sua capacidade e desenho institucional) constituiria não só violação ao princípio da separação de poderes, mas, também, uma atuação autoritária (com ideias contramajoritárias e viés não democrático) do Poder Judiciário.

No entanto, não há dúvida, pelo menos em teoria, sobre a vocação democrática dos Centros de Inteligência instituídos a partir da Portaria 2017/00369 do Conselho da Justiça Federal, uma vez que permitem a promoção do diálogo não só entre instâncias do Poder Judiciário, mas, também, a partir da provocação e/ou participação de qualquer pessoa física ou jurídica, pública ou privada.

Tal percepção é extraída de forma clara da própria redação da citada portaria, que prevê, entre outras competências do Centro de Inteligência nacional:

Organizar reuniões e propor encontros e seminários com membros do PoderJudiciário, do Ministério Público, das Defensorias Públicas, da Ordem dos Advogadosdo Brasil, do Poder Executivo, do Poder Legislativo, de organizações da sociedade civil,das universidades, de estudiosos e outros 
que, de qualquer modo, possam contribuirpara o debate e apresentação de propostas que visem ao aprimoramento da prestação jurisdicional.

A participação e a influência, na construção da solução, entre todos os envolvidos, independentemente do papel que exercem (ou não exercem) na seara judicial é um dos grande focos dos Centros de Inteligência e não é por outra razão que o Conselho da Justiça Federal também deixou expresso que cabe aos Centros de Inteligência locais "convidar as partes e advogados, públicos ou privados, com o objetivo de buscar a rápida solução para litígios que estejam impactando negativamente uma ou mais unidade jurisdicional".

Neste contexto, parece claro que um dos objetivos dos centros é a instrumentalização e abertura do diálogo interinstitucional. Seu funcionamento, assim, pressupõe essencialmente uma lógica colaborativa e é exatamente essa concepção dialógica e democrática que marca as novas estruturas judiciais.

Através delas, não só o Judiciário aparenta repensar seu papel clássico, como já dito, mas, também parece reconhecer que não existe, a princípio, decisão correta e justa que não conte com a efetiva participação das partes em sua construção.

\section{Os Centros de Inteligência e a prevenção de litígios judiciais.}

Segundo Cândido Rangel Dinamarco (DINAMARCO, 2008), "ao Estado Social contemporâneo repugna a inércia do juiz expectador e conformado; o juiz há de ter a consciência da função que, como agente estatal, é encarregado de desempenhar perante a sociedade".

Com efeito, nos dias de hoje, foge-se da ideia de que, no fazer cumprir a lei, no dizer $o$ direito, "exauria-se a ideia de promover justiça mediante o exercício da jurisdição" (DINAMARCO, 2008).

Neste contexto, a feição clássica e verticalizada da autoridade judicial (inspirada na perspectiva de Oskar Büllow (BÜLOW, 1868), já não faz mais sentido na sociedade democrática contemporânea, onde o juiz, a par de suas funções clássicas, deve, também, atuar como promotor do diálogo como instrumento para a busca de soluções e prevenção de litígios.

Marco Bruno de Miranda Clementino, juiz federal do Tribunal Regional Federal da

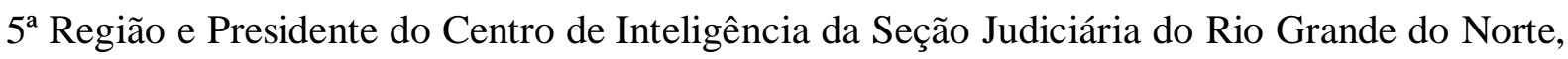
posiciona-se de forma irretocável sobre o assunto, em trabalho ainda inédito (CLEMENTINO, 2018, no prelo): 
Não se trata, portanto, da superação da inércia como princípio da jurisdição. O juiz permanece com os "olhos vendados" quando é provocado a atuar no plano contencioso, decidindo litígios. Porém, isso não afasta a sua função de gestor na promoção do diálogo e do tratamento adequado dos conflitos, assumindo sua função caráter administrativo. Assim, ainda que "cego", não se pode afirmar que o juiz contemporâneo deva ser "amordaçado". Não mais se concebe um juiz que não dialogue com a sociedade com o objetivo de atuar institucionalmente como gestor na solução de conflitos.

Nesta perspectiva, a Portaria $n^{\circ} 2017 / 00369$ do Conselho da Justiça Federal, estabelece que, além de sua função no gerenciamento de precedentes, cabe ao Centro Nacional de Inteligência:

a) trabalhar na prevenção dos motivos que ensejam o ajuizamento de demandas judiciais repetitivas ou de massa, a partir da identificação das possíveis causas geradoras do litígio;

b) acompanhar e monitorar o ajuizamento de demandas judiciais repetitivas ou de massa na Justiça Federal, a partir de relatórios a serem elaborados pelos Grupos Locais, com a finalidade de propor soluções para os conflitos e prevenir futuros litígios;

c) emitir notas técnicas referentes às demandas judiciais repetitivas ou de massa, notadamente para a uniformização de procedimentos administrativos e jurisdicionais e para o aperfeiçoamento da legislação sobre a controvérsia em debate;

d) sugerir à Presidência dos Tribunais Regionais Federais e ao Presidente da Turma Nacional de Uniformização a adoção de mutirões de julgamentos de processos que versem sobre idêntica matéria, bem como propor soluções de natureza não jurisdicional em face de conflitos repetitivos ou de massa;

e) propor medidas para o aperfeiçoamento procedimental das rotinas cartorárias dos Tribunais Regionais Federais no processamento de feitos que tenham recebido a mesma solução;

f) fomentar a implementação de medidas preventivas e de projetos de soluções alternativas de conflitos;

g) coordenar a instalação e supervisionar o funcionamento dos Centros Locais de Inteligência no âmbito dos Tribunais Regionais Federais brasileiros, bem como a 
comunicação entre eles e os Núcleos de Gerenciamento de Precedentes dos Tribunais Regionais Federais;

h) propor ou realizar estudos sobre as causas e consequências do excesso de litigiosidade na Justiça Federal;

i) organizar reuniões e propor encontros e seminários com membros do Poder Judiciário, do Ministério Público, das Defensorias Públicas, da Ordem dos Advogados do Brasil, do Poder Executivo, do Poder Legislativo, de organizações da sociedade civil, das universidades, de estudiosos e outros que, de qualquer modo, possam contribuir para o debate e apresentação de propostas que visem ao aprimoramento da prestação jurisdicional na matéria relacionada às atribuições do Centro Nacional;

j) realizar audiências públicas visando à busca de subsídios para estudo dos temas submetidos à sua apreciação.

A seu turno, competem aos centros locais de inteligência:

I - apresentar ao Centro Nacional, mediante iniciativa própria ou por solicitação, fatos e dados inerentes a demandas judiciais repetitivas ou com grande repercussão social para subsidiar os trabalhos na atuação estratégica de gestão processual e de precedentes;

II - identificar e monitorar, por meio de estudos e levantamentos, incluindo dados estatísticos, as demandas judiciais repetitivas ou de massa, bem como os temas que apresentam maior número de controvérsias;

III - propor ou realizar estudos sobre as causas, consequências do excesso de litigiosidade e estimativa de custo econômico das demandas identificadas no âmbito de competência jurisdicional da Seção;

IV - convidar as partes e advogados, públicos ou privados, com o objetivo de buscar a rápida solução para litígios que estejam impactando negativamente uma ou mais unidade jurisdicional;

V - propor ao Centro Nacional medidas concretas e normativas voltadas à modernização de rotinas processuais, organização, especialização e estruturação das unidades judiciárias atingidas pelo excesso de litigância, em integração com os Tribunais Regionais Federais e Cortes Superiores;

VI - elaborar propostas e ações coordenadas com instituições públicas visando ao combate da fragmentação na resolução dos conflitos; 
VII - organizar reuniões e propor encontros e seminários com membros do Judiciário, do Ministério Público, das Defensorias Públicas, da Ordem dos Advogados do Brasil, do Poder Executivo, do Poder Legislativo, de organizações da sociedade civil, das universidades, de estudiosos e outros que, de qualquer modo, possam contribuir para o debate e apresentação de propostas que visem ao aprimoramento da prestação jurisdicional na matéria relacionada às atribuições do Centro Nacional.

Como é possível se observar, os Centros de Inteligência têm uma clara proposta voltada à prevenção de litígios e, mais do que isso, à elaboração de estratégias diversas de enfrentamento de lides e feitos judiciais, sem esquecer a grande característica da litigiosidade na Justiça Federal: os repeat players.

Segundo Rodolgo de Camargo Mancuso (MANCUSO, 2015), uma das concausas da já mencionada crise numérica do sistema judicial brasileiro é a existência dos chamados litigantes habituais e essa percepção, como é possível observar, guiou a própria ideia dos Centros de Inteligência.

Os repeat players não só contribuem para grande parte das demandas repetitivas que assoberbam o Poder Judiciário, mas, também, afetam a forma como o sistema atua. Naturalmente, mais acostumados com as agruras e benesses da disputa judicial, os litigantes habituais geram uma desigualdade na distribuição dos ônus e encargos processuais.

Na Justiça Federal, por sua competência específica, os órgãos estatais ocupam, sem sombra de dúvida, o papel dos maiores litigantes do sistema. Questões previdenciárias, assistenciais, administrativas, financeiras e tributárias permeiam o dia a dia dos operadores do direito que transitam pelas dependências das varas federais.

Embora recentemente estruturados, já é possível identificar a atuação de alguns desses centros na prevenção de litígios, especialmente com os repeat players. Para este trabalho específico, interessante apontar a experiência do mais profícuo dos centros instituídos (e o primeiro deles): aquele instalado na Seção Judiciária do Rio Grande do Norte.

Desde setembro de 2016, antes mesmo da Portaria $n^{\circ}$ 2017/00369 do Conselho da Justiça Federal, o Centro de Inteligência da Justiça Federal do Rio Grande do Norte já atuava sob o nome de "Comissão de Prevenção de Demandas". Possui página virtual própria (https://www.jfrn.jus.br/vara/quem-somos.html?id=51) e apresenta 21 (vinte e um) temas afetados pela inovadora estrutura judicial, de questões envolvendo criminalização da pesca da lagosta por intermédio do mergulho (tema 0018/2017) a cobrança de anuidade de conselhos profissionais (tema 0008/2016).

Revista de Política Judiciária, Gestão e Administração da Justiça | e-ISSN: 2525-9822 | Salvador | v. 4 | n. 1 | p. $41-57$ | Jan/Jun. 2018 
Embora não haja procedimento estabelecido para o tratamento dos temas afetados, é possível observar que uma estratégia envolvendo convites para reuniões, levantamento de dados estatísticos, realização de audiências públicas e emissão de recomendações é colocada em prática pelos componentes do centro.

Em março de 2018, 10 (dez) notas técnicas haviam sido emitidas a partir do trabalho com os temas afetados, são elas:

\begin{tabular}{|c|c|c|}
\hline TEMA & NOTA TÉCNICA & ASSUNTO \\
\hline $0020 / 2017$ & $\begin{array}{l}0003 / 2017 \\
0002 / 2017\end{array}$ & $\begin{array}{l}\text { Cadastramento de pessoas jurídicas em sistemas } \\
\text { processuais eletrônicos }\end{array}$ \\
\hline $0015 / 2017$ & $0004 / 2017$ & $\begin{array}{l}\text { Cessão de crédito. Caixa econômica federal. } \\
\text { Condições da dívida. Legalidade do repasse. }\end{array}$ \\
\hline $0011 / 2016$ & $0003 / 2016$ & $\begin{array}{l}\text { Múltiplas demandas idênticas. } \\
\text { assentamento rural zabelê. INCRA, título de } \\
\text { posse. Indenização por danos morais. }\end{array}$ \\
\hline $0010 / 2016$ & $0002 / 2016$ & $\begin{array}{l}\text { Portaria MF n. }{ }^{\circ} \text { 156/99. Instrução normativa SRF } \\
n^{\text {o }} \text { 096/99. Limites à importação de bens. } \\
\text { Legalidade. }\end{array}$ \\
\hline $0008 / 2016$ & $0004 / 2016$ & $\begin{array}{l}\text { Certidão negativa de débitos ou positiva com } \\
\text { efeito de negativa. Postulação judicial. } \\
\text { Multiplicidade de demandas. Indeferimento } \\
\text { administrativo. }\end{array}$ \\
\hline $0007 / 2016$ & $0006 / 2016$ & $\begin{array}{l}\text { Conselhos profissionais. Cobrança de anuidades. } \\
\text { Multiplicidade de demandas judiciais. Política de } \\
\text { conciliação. }\end{array}$ \\
\hline $0006 / 2016$ & $0005 / 2016$ & $\begin{array}{l}\text { Benefício de prestação continuada. Ausência de } \\
\text { parâmetros para concessão. Multiplicidade de } \\
\text { demandas judiciais. }\end{array}$ \\
\hline $0004 / 2016$ & $0001 / 2016$ & $\begin{array}{l}\text { SFH. Vício construtivo. Seguro. Múltiplas } \\
\text { demandas idênticas. Litisconsórcio ativo } \\
\text { multitudinário. Caixa. Legitimidade passiva. }\end{array}$ \\
\hline $0001 / 2016$ & $0007 / 2016$ & PSS. Valores percebidos por servidores públicos. \\
\hline
\end{tabular}




\begin{tabular}{|l|l|l|}
\hline & & Desconto. Determinação judicial. \\
\hline & & \\
\hline
\end{tabular}

Cada tema traz em sua afetação alguma característica que distingue o trabalho do Centro de Inteligência.

À guisa de exemplo, o tema $n^{\circ}$ 0008/2016, que diz respeito à emissão de certidão negativa de débitos ou positiva com efeito de negativa, foi afetado a pedido da Procuradoria da Fazenda Nacional, que identificou um número considerável de postulações judiciais de fornecimento de certidões positivas com efeito de negativas de débitos federais (fazendários e previdenciários), sempre acompanhadas exclusivamente da negativa de outorga do documento extraída do mero acesso ao link disponível na rede mundial de computadores, como prova da suposta violação do direito subjetivo do contribuinte.

Os estudos e discussões conduzidas resultaram na Nota Técnica $n^{\circ} 4 / 2016$, a qual, entre outras recomendações, orienta que as varas federais exijam decisão administrativa específica, proferida em decorrência de protocolo formal perante a administração tributária, realizado pelo interessado com requerimento para emissão do documento e que não seja aceita a mera cópia da tela do link em que disponibilizada a consulta eletrônica da certidão como prova de seu indeferimento administrativo.

Já o tema 0001/2016 foi afetado a pedido da Direção do Foro da Seção Judiciária, com vistas a estabelecer critérios para encaminhamento dos autos à Contadoria do Foro e indicar determinadas demandas nas quais o cálculo pode ser elaborado na própria vara, em razão da simplicidade e da disponibilidade de planilha pela contadoria.

Após os estudos conduzidos, foi sugerido o debate entre os juízes da subseção sobre as recomendações da Contadoria e o agendamento de curso para o início de 2017, a contar com a participação da Contadoria do Foro, diretores de secretaria e servidores do setor de cumprimento, a fim de uniformizar procedimentos e conferir maior celeridade ao trâmite dos processos que demandam cálculos judiciais menos complexos.

Com relação ao tema 0018/2017 (ainda sem conclusão), a nota distintiva é que foi uma demanda surgida a partir de reiteradas ações penais propostas contra pescadores de lagostas potiguares e os estudos estão sendo conduzidos no sentido de reformulação do entendimento administrativo que culmina por criminalizar a conduta dos pescadores. 
A partir da breve análise dos elementos que envolvem o trabalho em um Centro de Inteligência judicial, é possível observar que o tratamento e prevenção de litígios fora do processo, mas, ainda, na seara judicial, está em fase inicial, mas bem diversificada. Porém, algumas notas já sobressaem e são comuns: diálogo interinstitucional permanente, democratização na afetação dos temas e estudos técnicos de soluções que permitem um funcionamento dotado de cientificidade ao sistema judicial.

\section{Conclusão}

A partir dos pontos apreciados no presente artigo, podemos concluir que o Poder Judiciário brasileiro enfrenta, atualmente, uma das maiores crises da sua história. Segundo o relatório "Justiça em Números", do Conselho Nacional de Justiça, embora o número de casos resolvidos (sentenças prolatadas ou processos baixados) aumente a cada ano, também aumenta o número de feitos pendentes de julgamento (que, no ano de 2016 alcançou a marca de 79 milhões) e, consequentemente, da taxa de congestionamento respectiva.

Assim, quando se fala no sistema judicial contemporâneo, questões como seu papel dentro da sociedade e a própria noção da expressão acesso à justiça são colocados na mesa de discussão.

De fato, embora se reconheça que a facilitação da solução da lide através da intervenção de um terceiro (triangularidade), é importante ter em mente que a construção da melhor solução não pode ser algo imposto aos envolvidos, a menos que isso seja absolutamente necessário (no caso de impossibilidade jurídica, técnica ou emocional de conciliação).

A proposta de maior democratização da Justiça e mesmo de reformulação da função judicial clássica começou a ser concretizada no Brasil, dentro do Poder Judiciário, a partir da Resolução n. 125/2010 do Conselho Nacional de Justiça, que dispôs sobre a Política Judiciária Nacional de tratamento adequado dos conflitos de interesses no âmbito do Poder Judiciário.

O chamado sistema multiportas de solução de conflitos, instituído a partir da partir da Resolução n. 125/2010 do Conselho Nacional de Justiça, oferece ao jurisdicionado diversas ferramentas, processuais ou não, de resolução do litígio, partindo do pressuposto, constante nos considerandos da referida resolução de que "o direito de acesso à Justiça, 
previsto no art. $5^{\circ}, \mathrm{XXXV}$, da Constituição Federal além da vertente formal perante os órgãos judiciários, implica acesso à ordem jurídica justa e a soluções efetivas”.

Foi com a percepção da necessidade de uma reformulação do papel do Poder Judiciário dentro da sociedade que, em 19 setembro de 2017, o Conselho Nacional de Justiça editou a Portaria 2017/00369 criando o Centro Nacional de Inteligência da Justiça Federal, com as finalidades, dentre outras, de trabalhar na prevenção de demandas judiciais repetitivas ou de massa, fomentar a implementação de medidas preventivas e de projetos de soluções alternativas de conflitos e propor soluções judiciais e administrativas para o manejo de litígios.

Um dos objetivos dos Centros de Inteligência é a instrumentalização e abertura do diálogo interinstitucional. Seu funcionamento, assim, pressupõe essencialmente uma lógica colaborativa e é exatamente essa concepção dialógica e democrática que marca as novas estruturas judiciais. Através delas, não só o Judiciário aparenta repensar seu papel clássico, como já dito, mas, também parece reconhecer que não existe, a princípio, decisão correta e justa que não conte com a efetiva participação das partes em sua construção.

Os citados centros têm uma proposta voltada à prevenção de litígios e, mais do que isso, à elaboração de estratégias diversas de enfrentamento de lides e feitos judiciais, sem esquecer a grande característica da litigiosidade na Justiça Federal: os repeat players.

Embora não haja procedimento estabelecido para o tratamento dos temas afetados, é possível observar que uma estratégia envolvendo convites para reuniões, levantamento de dados estatísticos, realização de audiências públicas e emissão de recomendações é colocada em prática pelos componentes do centro.

Ante o exposto, a partir da breve análise dos elementos que envolvem o trabalho em um Centro de Inteligência judicial, é possível observar que o tratamento e prevenção de litígios fora do processo, mas, ainda, na seara judicial, está em fase inicial, mas bem diversificada. Porém, algumas notas já sobressaem e são comuns: diálogo interinstitucional permanente, democratização na afetação dos temas e estudos técnicos de soluções que permitem um funcionamento dotado de cientificidade ao sistema judicial.

\section{Referências bibliográficas.}

ALVIM, J. E. (1989). Elementos de teoria geral do processo. Rio de Janeiro: Forense. 
ARGUELHES, D. W., \& Leal, F. (jan/jun de 2011). O argumento das "capacidades institucionais" entre a banalidade, a redundância e o absurdo. Direito Estado $e$ Sociedade, pp. 6-50.

AUGSBERGER, D. W. (1992). Conflict mediation across cultures. London: Westmister/John Knox Press.

BÜLOW, O. V. (1868). La Teoría de las Excepciones Procesales y los Presupuestos Procesales. Buenos Aires: Ediciones Juridicas Europa - America.

CAPELlETTI, M. (1988). Acesso à Justiça. Porto Alegre: Sergio Fabris.

CLEMENTINO, M. B. (2018, no prelo). Centro local de inteligência da Justiça Federal potiguar: legitimidade pelo diálogo.

DINAMARCO, C. R. (2008). A instrumentalidade do processo. São Paulo: Malheiros Editores.

MANCUSO, R. d. (2015). Acesso à Justiça: condicionantes legítimas e ilegítimas. São Paulo: Revista dos Tribunais.

NUNES, D., \& Bahia, A. (jul/dez de 2010). Processo, jurisdição e processualismo constitucional democrático na América Latina: alguns apontamentos. Revista Brasileira de Estudos Políticos, pp. 61-96. 